\title{
Assessing the sustainability content of the Nigerian engineering curriculum
}

\author{
Usman U Akeel ${ }^{1}$ \\ $\mathrm{PhD}$ \\ Department of Civil and Environmental Engineering \\ Air Force Institute of Technology - Kaduna \\ Nigeria \\ E-mail : u.akeel@afit.edu.ng \\ Sarah J Bell \\ Director, UCL Engineering Exchange \\ University College London \\ London, UK \\ E-mail : s.bell@ucl.ac.uk \\ John E Mitchell \\ Professor \\ Department of Electronic and Electrical Engineering \\ University College London \\ London, UK \\ E-mail : j.mitchell@ucl.ac.uk
}

\begin{abstract}
Purpose - The purpose of this study is to present an assessment of the sustainability content of the Nigerian engineering curriculum in universities.

Design/methodology/approach - Content analysis is used to generate and analyse data from three engineering documents, namely the Benchmark Minimum Academic Standards for Engineering Programmes in Nigeria, and the engineering handbooks of two Nigerian higher education institutions.
\end{abstract}

Findings - The Nigerian engineering curriculum is revealed to have a low sustainability content, with environmental concepts being the most cited themes and social topics as the least stated issues.

Research limitations/implications - The sustainability assessment approach adopted in the study is constrained by the question of what constitutes a sustainability syllabus. Expert-derived sustainability themes employed in the study are unavoidably incomplete and may limit the conduct of an exhaustive sustainability content assessment.

Practical implications - Based on the research outcome, the Council for the Regulation of Engineering in Nigeria and other stakeholders can consider ways to adequately incorporate sustainability themes in the Nigerian engineering curriculum.

Originality/value - The research is an effort to determine the presence of sustainability issues in the Nigerian engineering education, which has hitherto been scarcely documented. This study provides a baseline and a rationale for sustainability education interventions in the Nigerian

\footnotetext{
${ }^{1}$ Usman Akeel

usman.akeel.09@ucl.ac.uk
} 
engineering curriculum. It also presents a methodology for analysing sustainability content in university curriculum and contributes to the continuing sustainability education discourse, especially in relation to sub-Saharan Africa.

Keywords Sustainability, Assessment, Content, Curriculum, Engineering education, Nigeria

Paper type Research paper

\section{Introduction}

In 2004, the Barcelona Declaration (EESD, 2004) presented a sustainability narrative of increasing complexity and the inadequacies of the dominant socioeconomic development model. A new kind of engineer was needed, possessing such skills as an understanding of engineering's interface with society, economy and environment. Also recommended were the application of systemic and holistic methods, ability to work in multidisciplinary teams, and the capacity to utilise professional knowledge according to deontological principles and universal ethics. Engineering education must be reoriented towards achieving these competences (EESD, 2004). These ideas made inroads into the educational policies of several governments, with accreditation organisations introducing sustainability as a certification requirement.

Sweden modified the Swedish Higher Education Act (1992:1434) in 2006 to mandate universities to promote sustainable development through their educational activities (Motrel et al., 2006) Similarly, the UK Standard for Professional Engineering Practice (UK-SPEC) captured the issue of sustainability under its competence and commitment standards for various categories of practitioners (Engineering Council, 2013). Equally, the Council for the Regulation of Engineering in Nigeria (COREN) in 2014 updated its accreditation requirements with sustainability as a key item (BMAS, 2014). Such efforts continue to be replicated globally (Fenner et al., 2005; Kamp, 2006; Desha et al., 2007). In the developing world, engineering sustainability education is progressing slowly, but with potent signs of an acceleration (UNEP-MESA, 2009). African higher education institutions (HEIs) through the Association of African Universities (AAU) have acknowledged the indispensability of sustainability education in the twenty-first century (AAU, 2009). The 2009 Abuja Declaration featured the pledge of African universities to implement the Higher Education for Sustainable Development in Africa (HESDA) framework (AAU, 2009). Nonetheless, the progress of African engineering education for sustainability is not yet welldocumented (GUNi et al, 2011).

This paper assesses the sustainability content of the Nigerian engineering curriculum in order to contribute to the discourse of engineering education for sustainable development in Africa. The assessment involves an analysis of three engineering documents: the Benchmark Minimum Academic Standards for Undergraduate Engineering Programmes in Nigeria (BMAS) and the engineering handbooks of two Nigerian HEIs dubbed HEI-1 and HEI-2. The documents are examined against a priori codes obtained from an expert-derived list of sustainability themes. The study determines the extent to which these topics are covered in the Nigerian engineering curriculum. The paper proceeds with an overview of sustainability assessment, sustainability in engineering education research and the Nigerian experience. Thereafter, the methodology of the study and the results of the assessment are detailed. The paper concludes with a discussion of the findings and limitations of the study.

\section{Sustainability assessment in higher education}

Across different organisations, tools have been developed to evaluate sustainability initiatives. In higher education, sustainability assessments have focused on the customary university functions of education, research, community outreach, and operation (Lozano and Lozano, 2014). The education component of these evaluations usually features assessments vis-a-vis sustainability content. However, what qualifies as sustainability content is not readily intelligible as the concept 
of sustainability is fluid. Nonetheless, the point of departure for most researchers is the use of expert-derived sustainability themes. Some of these theme-based assessment tools include the Auditing Instrument for Sustainability in Higher Education (AISHE), Assessing Responsibility In Sustainable Education (ARISE), Graphical Assessment for Sustainability in Universities (GASU), and Sustainability Tool for Assessing Universities Curricula Holistically (STAUNCH).

AISHE is an assessment tool that was originally developed by the Dutch Committee on Sustainable Higher Education. The first version of the instrument designed in 2001 was reviewed in 2012 into AISHE 2012 by a HEI certification organisation dubbed Hobéon (Caeiro et al., 2013). The AISHE 2012 framework comprises four categories, namely objectives, people and resources, education, and results. Sustainability assessments in HEIs based on AISHE 2012 are premised on these four categories across five stages of development, namely activity-oriented, processoriented, system-oriented, chain-oriented, and society-oriented phases. The outcome of an AISHE 2012 audit is typically a verdict on the level of sustainability integration in an educational institution (Caeiro et al., 2013). The process of an AISHE 2012 audit is consensus-building and involves a programme representative group with at least two AISHE auditors. The focus of the instrument on a single educational programme, abstract criteria and dependence on representative groups are cited as drawbacks (Shriberg, 2002). Assessment of curricular sustainability content in AISHE 2012 is covered under the education module and is basically a subjective criterion-based process.

ARISE seeks to evaluate the sustainability and social responsibilities of HEIs. It is an instrument developed in response to educational institutions' need to manage and assess sustainability issues holistically. Hence, the purview of the ARISE tool is organisational typically covering an entire institution (Caeiro et al., 2013). Eleven themes featured in the ARISE instrument including vision and mission, policy, education, research, and service to society. Others are operations/planet, operations/people, operations/prosperity, students, professional field, and culture (Caeiro et al., 2013). These subjects are based on the international guideline for social responsibility of organisations, ISO 26000. ARISE audit proceeds with a documentary scrutiny by an appointed audit panel which undertakes site visits. Three possible outcomes of an ARISE assessment are "committed", "recognised", and "excellent", which describe the stage of a sustainability initiative in an educational institution. The education element of ARISE assesses the sustainability content of a curriculum in an inexplicit manner deferring to the audit panel's impression on some generic statements. This is considered a deficiency of the ARISE assessment tool.

GASU was developed as a modification of the Global Reporting Initiative Sustainability Guidelines intended to guide environmental, economic and social performance of organisations (Lozano, 2006). The creation of GASU aimed to adapt these guidelines for use in HEIs by adding an educational dimension. GASU is a graph-based assessment tool that facilitates the comparison of sustainability efforts between educational institutions. The instrument makes use of indicators scaled from 0 to 4 to automatically generate nine charts across the three sustainability pillars and the additional educational dimension (Lozano, 2006). The strength of GASU in being an indicatorbased tool benefits organisation by ensuring consistency which is vital for comparison and benchmarking. Nonetheless, the evaluation of sustainability content of a curriculum with the GASU instrument is not without limitations due to the added complexity of the educational dimension.

STAUNCH® (Sustainability Tool for Assessing Universities Curricula Holistically) is an education assessment tool developed in 2007 to benchmark the extent of a university curriculum's coverage of sustainability ideas (Lozano and Lozano, 2014). STAUNCH® analyses sustainability content of curricula by examining syllabi or course descriptors as data source based on 37 sustainability topics across economic, social, environmental and crosscutting dimensions. This implies that result accuracies are contingent on the credibility of the course information available and that unpublished course information cannot be captured. Nonetheless, the assessment tool has 
proved quite useful in sustainability education research in a growing number of HEIs including all universities in Wales and two universities in England (Caeiro et al., 2013). An important strength of the STAUNCH tool is its focus on the sustainability content of a curriculum to ascertain the extent to which sustainability themes are addressed.

An operational definition of sustainability content adopted in the present study is the spread or coverage of sustainability topics or themes in a curriculum stressing the interconnection of environment, economy, and society along with the multidimensional problem-solving strategies for addressing sustainability challenges. This definition was arrived at eclectically from the many scholarly attempts to delineate sustainability content, some of which have been reviewed in the preceding paragraphs. Guided by the goal of the present research to assess the sustainability content of the Nigerian engineering curriculum, the working definition embodies three concepts, namely sustainability, content, and curriculum. Whilst sustainability is conventionally depicted in the intersection of economy, society, and environment with multifaceted problem-solving ideas, content implies the sum of things included in a collection. Curriculum, on the other hand, typically represents a documentation of the philosophy, expected learning outcomes, description, outline, and assessment criteria of an educational programme (Kotecki, 2002). The operational definition of sustainability content used in the present study captures these intricacies which are fundamental to the concept of sustainability. However, none of the reviewed sustainability assessment tools perfectly matches this working definition excepting STAUNCH®. The sustainability topics featured in the STAUNCH ${ }^{\circledR}$ tool are adaptable for the purposes of the present study congruent with the operational definition.

\section{Sustainability in engineering education research}

Studies focusing on the sustainability content of engineering programmes have emerged in the literature. Beringer et al (2008) assessed the status of sustainability efforts in HEIs across Atlantic Canada. Their research examined the level of sustainability integration in the Canadian HEIs covering curriculum amongst other areas. The assessment used a questionnaire to obtain data, which were triangulated with a content analysis. The researchers found that the majority of the HEIs had responded positively to sustainability, with some deficiencies in the aspects of physical operations, staff development and student opportunities. The curricular sustainability content ranged from minimal to substantial, with three-quarter of the HEIs embedding sustainability into traditional disciplines. In a related work, Watson (2013) undertook a content analysis of the civil engineering curriculum at Georgia Institute of Technology and discovered that the integration of sustainability was biased towards the environmental dimension.. The findings substantiate the existence of a disproportionate spread of sustainability in the curriculum (Byrne et al., 2010; Segalas et al., 2010; Sinnott and Thomas, 2012; Shields et al., 2014; Sivapalan, 2015). Overall, Watson found a strong evidence of sustainability in the civil engineering curriculum.

Seeking answers to the questions of competences, pedagogy and curriculum in relation to sustainability in engineering education, Coral (2009) conducted a research of some European HEIs in Spain, Sweden, The Netherlands, Ukraine, Belgium, Scotland and England. The Eurocentric effort was guided by the European Higher Education Area (EHEA) framework with sustainability as a tripartite competence of knowledge/understanding, skills/abilities, and attributes. The study analysed how educational processes can provide suitable pedagogies to attain sustainability learning amongst engineering graduates (Coral, 2009). On the question of curriculum, there was a dissonance with the ideal situation which is expected to be piecemeal. The lack of sustainability comprehension, top-down and bottom-up collaboration contributed to this impasse. Nonetheless, the study found a strong presence of sustainability in the European engineering curricula.

In the African context, research into the sustainability content of engineering curriculum is scarce (Manteaw, 2012; Akeel et al., 2017). This is not unexpected of a region whose HEIs teach sustainability mainly "as a fringe aspect of a limited number of disciplines" (UNEP-MESA, 2009, p.20). Manteaw argues that besides the UN-backed Mainstreaming Environmental Sustainability 
in African Universities (MESA), there is no visible sustainability education programme in West Africa. The studies that have considered sustainability learning on the continent have generally reported a low sustainability presence in the curriculum (UNEP-MESA, 2009; GUNi et al., 2011; UNESCO, 2014; Etse and Ingley, 2016). In Ghana, Etse and Ingley studied a polytechnic programme and discovered that sustainability courses were largely absent from the curriculum. Social sustainability appeared more than the environmental and economic themes. Contrastingly, in a case study of Rhodes University in South Africa, Togo (2009) discovered that sustainability had permeated teaching, research, and operations of the university. Although it did not feature engineering courses, the study found the sustainability content of the programmes to range from nil (accounting) to high (environmental sciences).

\section{Nigerian engineering curriculum and sustainability}

The Federal Ministry of Education in Nigeria has the mandate to formulate and oversee national educational policies (FME, 2016). The educational policies through the National Universities Commission (NUC) contribute in shaping the route to an engineering career in Nigeria. Currently, an engineering degree in Nigeria is acquired over a five-year period in 160 Nigerian universities, comprising 86 public and 74 private HEIs (NUC, 2018). The Nigerian engineering curriculum is standardised by COREN in conjunction with NUC and the universities. In fulfilment of its function to determine the quality of knowledge and skills for a professional engineering career in Nigeria, COREN sets the minimum academic standards for all engineering programmes in the country. This serves as a guideline to which all Nigerian universities refer for the development of their engineering syllabi. However, the prevalence of sustainability in the Nigerian engineering curriculum is not well-documented. Thus, it is difficult to ascertain whether any difference subsists in the sustainability education initiatives between the private and public HEIs in Nigeria. The reviews of relevant documents indicate that some environmental courses such as environmental management science, environmental technology and environmental engineering are contained in the engineering curriculum (Akinsanya, 2013; BMAS, 2014; JAMB, 2017). Sixteen Nigerian universities presently offer such programmes (JAMB, 2017). Nonetheless, engineering education for sustainability has not gained much recognition in Nigeria (Akeel et al., 2017). There is no Nigerian HEI that presently offers a sustainable engineering degree ${ }^{2}$. Furthermore, sustainability assessment studies on the Nigerian engineering curriculum are rare (Akeel, 2011; GUNi et al., 2011). Such an assessment is needed as a baseline for sustainability education interventions.

\section{Methods}

\section{Data collection}

Content analysis was used to generate data from three engineering documents: the BMAS document as well as HEI-1 and HEI-2 engineering handbooks. Table 1 is a list of the programmes contained in the engineering documents. The intention of the study was to cover as many Nigerian HEIs as possible including private and public universities. Consequently, around 20 Nigerian universities were invited to participate in the study out of which five responded positively. Of these, only two provided access to the electronic copies of their engineering handbooks. Thus, the willingness of the universities to participate in the research as well as the availability of the engineering manuals informed the choice of the two HEIs. Given that the involvement of the HEIs in the study was to gauge the sustainability content of the operational curriculum vis-à-vis the minimum standard of the BMAS document, the use of the two engineering handbooks is fit for purpose. The downside of this pragmatism, however, is that it constrains the ability of the research to draw parallels between private and public universities since both HEI-1 and HEI-2 are public institutions.

\footnotetext{
${ }^{2}$ This is based on the JAMB Brochure which contains all the courses offered in Nigerian HEIs as well as the universities offering these courses.
} 


\section{BMAS document}

The BMAS is a document issued and reviewed episodically by COREN to set out standards for undergraduate engineering programmes in Nigeria. A 367-page document, the BMAS lists 30 programmes with a description of required and common courses. The document is divided into three parts, namely general requirements, specific requirements and accreditation score sheet. The document is an outcome of deliberations by practitioners and academics including deans and heads of engineering departments. Each Nigerian HEI submits the syllabi of its engineering programmes. A workshop is held to deliberate on these submissions. Courses are included in the BMAS on the basis of global best practice and contextual relevance. The BMAS standardises the syllabi and becomes the official guideline for all undergraduate engineering programmes in Nigeria. The details in the BMAS represent the minimum requirements for all engineering programmes in Nigeria and provide a panorama of the Nigerian engineering curriculum. Hence, an engineering institution that exclusively adopts the BMAS-listed courses and contents will have fulfilled the requirements for awarding engineering degrees. Therefore, the BMAS descriptions capture what is deemed an adequate engineering curriculum in Nigeria. The preamble of the document itemises nine learning outcomes. Item 6 states that "a graduate of an engineering programme accredited by COREN is expected to have the ability to consider the environment and sustainability in finding solutions to problems" (BMAS, 2014, p.13). The BMAS manual informs all handbooks of engineering faculties. Furthermore, Nigerian HEIs refer to the BMAS document for purposes of accreditation and curricular development. The manual is the basis upon which COREN accredits engineering programmes. The mention of sustainability as a competence expected of engineering graduates is reassuring. However, this can only be effective with an actual sustainability integration in the programmes. The documentary analysis set out to discover if such an alignment existed.

\section{HEI-1 \& HEI-2 engineering handbooks}

Nigerian HEIs usually maintain engineering handbooks modelled on the BMAS. HEI-1 \& HEI-2 engineering handbooks were obtained from the two Nigerian HEIs that participated in the present study. Both engineering handbooks provide details of the various engineering programmes in the HEIs. Whilst HEI-1 details nine engineering disciplines, HEI-2 particularises three engineering programmes. The documents contain information on admission requirements, student workload, grading system, course title, course description, expected learning outcomes, and course content. Information on various topics covered under each course is equally provided. Each course is prefaced by a list of learning outcomes suggesting what students are expected to learn from the course. Although the descriptions in engineering handbooks may be somewhat generic, they are nonetheless useful indicators of what is taught or learned in an engineering class. The handbooks are customarily designed and reviewed by the engineering faculties based on departmental inputs. A faculty administrator collates inputs and prepares a draft to be deliberated on at a faculty meeting. The terms of reference for the meeting include the COREN-issued BMAS document. Final approval for the engineering handbooks is granted by the faculty dean. Hard copies of the documents are normally distributed to students, whilst soft copies are uploaded to faculty websites. The HEI-1 \& HEI-2 engineering handbooks used in the present study were obtained directly from the education institutions. The descriptions of the engineering programmes contained in the two documents, even though, featured learning outcomes, might not be wholly representative of what is assessed in the engineering students. To assess what students actually learn about sustainability, the students would be required to undertake a sustainability literacy test such as The Sulitest - a web-based international literacy test instrument developed to examine global awareness of core sustainability knowledge and skills (Carteron and Decamps, 2017). However, for the purpose of a document-specific sustainability content assessment such as the one undertaken in the present study, these engineering handbooks suffice. 
Table 1. Programmes in the engineering documents

\begin{tabular}{lll} 
BMAS & HEI-1 Engineering & $\begin{array}{l}\text { HEI-2 Engineering } \\
\text { Handbook }(\mathbf{n = 3})\end{array}$ \\
\hline $\begin{array}{l}\text { Aerospace, Agricultural, Automotive, } \\
\text { Biomedical, Ceramic, Chemical, Civil, }\end{array}$ & $\begin{array}{l}\text { Agricultural, Chemical, } \\
\text { Civil, Electrical, Electronic, }\end{array}$ & $\begin{array}{l}\text { Civil, Electrical \& } \\
\text { Electronic, Mechanical }\end{array}$ \\
$\begin{array}{l}\text { Environmental, Food, Gas, Industrial \& } \\
\text { Production, Industrial, Marine, Mechanical, }\end{array}$ & $\begin{array}{l}\text { Mechanical, Metallurgical } \\
\text { \& Material, Water }\end{array}$ & \\
$\begin{array}{l}\text { Mining, Petrochemical, Petroleum, } \\
\text { Production, Public Health, Refrigeration \& }\end{array}$ & Eesources \& & \\
Air-Conditioning, Structural, Systems, & & \\
Textile \& Polymer, Water Resources, & & \\
Wood Products & & \\
\hline
\end{tabular}

\section{Data assessment}

The question that informed the content analysis was whether or not sustainability topics were covered in the engineering handbooks. It was therefore of interest to analyse the mentions of a sustainability topic in the engineering programmes listed in the documents. The analysis involved the use of NVivo 11 Pro software. The engineering documents were converted to an editable PDF form, uploaded into the NVivo 11 Pro software and filed appropriately. Each engineering document was treated as a separate project. Thirty engineering programmes described in the BMAS document with the common engineering courses formed a total of 31 cases. The nine engineering programmes detailed in the HEI-1 engineering handbook and common engineering courses yielded a total of 10 cases, whilst the three courses of HEI- 2 engineering document with the common courses produced a total of four cases. A priori codes based on the four categories of environmental, economic, social, and crosscutting themes became parent nodes. In line with the STAUNCH® sustainability themes, the environment node had 9 child nodes. Similarly, economic topics gave rise to 6 child nodes under the economic parent node, while the social parent node had 12 child nodes derived from myriad social issues like poverty, bribery, corruption, equity, etc. The crosscutting node contained 10 child nodes based on a range of multidimensional themes such as systems thinking, responsibility, holistic thinking, etc. The engineering documents were then scrutinised and coded at the cases and nodes.

Words such as 'sustainable' used in the literal sense were not coded. Topics had to clearly embody sustainability ideas before being coded. Descriptive statistics for each engineering document were obtained and tabulated based on the model of Table 2.

Table 2. Model for descriptive statistics of engineering documents

\begin{tabular}{lcccc}
\hline Sustainability Theme & Frequency & $\begin{array}{c}\text { Expected } \\
\text { Occurrence }\end{array}$ & $\begin{array}{c}\text { \% within Potential } \\
\text { Theme Content }\end{array}$ & $\begin{array}{c}\text { NVivo \% } \\
\text { within } \\
\text { Document }\end{array}$ \\
\hline Subtopic 1 & $\mathrm{x}$ & $\mathrm{x}$ & $\mathrm{x}$ & $\mathrm{x}$ \\
\hline Subtopic 2 & $\mathrm{x}$ & $\mathrm{x}$ & $\mathrm{x}$ & $\mathrm{x}$ \\
\hline Subtopic 3 & $\mathrm{x}$ & $\mathrm{x}$ & $\mathrm{x}$ & $\mathrm{x}$ \\
\hline Theme content (Total) & $\mathrm{x}$ & $\mathrm{x}$ & $\mathrm{x}$ & $\mathrm{x}$ \\
\hline
\end{tabular}

The sustainability theme column featured the four categories of economic, environmental, social and crosscutting topics and their subtopics, whilst the frequency column was used to enter the number of mentions of a subtopic obtained from NVivo as references coded. The process of obtaining the frequencies of themes from textual data is sometimes referred to as quantitising. 
Quantitising aided the numerical translation of the qualitative data uploaded to NVivo by focusing on the number of times sustainability themes appeared in the dataset. Therefore, the frequencies are numerical representations of the parts of the data that have been coded as sustainability themes. A frequency search on NVivo returned the number of occurrences of a code, and by implication, that of a sustainability theme.

The expected occurrence column contained an anticipated mention of sustainability theme in the engineering documents, expressed as a function of the number of engineering programmes detailed in the documents. The assumption was that each aspect of sustainability should be mentioned, at the least, once in each engineering programme. It is reasoned that a singular mention of sustainability in the curriculum of an engineering programme should be the minimum expectation for sustainability presence. This aligns with the widely-accepted approach of piecemeal sustainability integration in the engineering curricula that begins with concepts introduction through dedicated lectures and tutorials (Azapagic et al., 2005). Thus, an assessment of a preintervention curriculum could aptly proceed with a focus on the minimum expected sustainability presence. Consequently, the expected occurrence of sustainability themes in the BMAS document, HEI- 1 and HEI-2 engineering handbooks was 31, 10 and 4 respectively (Table 1), which severally reflect the number of the engineering programmes in the documents. Each sustainability subtheme was expected to be mentioned in the three documents accordingly. The calculation of the percentage within potential theme content was based on the formula: (Frequency/Expected Occurrence) $X 100$. This equation provided an idea of how a sustainability theme, based on its spread potential, fared in terms of coverage within an engineering document.

The last column on the table featured the percentage within an engineering document obtained directly from NVivo calculations. The NVivo percentage coverage for PDF documents is conventionally the average of the percentage of characters coded and the percentage of the page area coded. The outcome of this average is expressed as a percentage of the total document. The percentage of an engineering document covering a sustainability theme was calculated for all the documents and sustainability themes. The theme content row was used to calculate the sum of the entries in all the columns, which resulted in an overall assessment of the theme's content in the relevant engineering document. Additionally, the location of a sustainability theme in an engineering document, that is, the engineering programme in which a mention(s) of sustainability occurred was traced and presented on a stacked bar chart.

\section{Results}

\section{BMAS for engineering}

The BMAS document was analysed for its sustainability content based on four sustainability themes: economic, environmental, social and cross-cutting topics. The results of the analysis are presented in the succeeding sections.

\section{Economic content}

Figure 1 shows the spread of economic themes across 30 engineering programmes contained in the BMAS document. Only 13 programmes covered five of six economic topics with one economic theme, namely GNP, not mentioned in any of the programmes. There was no engineering programme that featured all the economic topics. However, the economic concept of accountability was covered in the common engineering courses. A recurring economic theme in the BMAS was production \& consumption patterns. This theme occurred four times in chemical engineering courses and once each in agricultural, biomedical, civil, communications, gas, mechanical, and mining engineering as well as in petrochemical, petroleum, and wood products engineering courses. Hence, $16 \%$ of the potential BMAS economic content featured in the document, which corresponded to $0.65 \%$ of the BMAS (Table 3 ). 


\section{Environmental content}

The environmental content of the BMAS document is shown in Figure 2. Across the engineering programmes, five of nine environmental themes featured in only 11 disciplines with environmental engineering covering up to four topics. Engineering disciplines which covered at least one of the five featured themes included civil, chemical, mechanical, mechatronics, and metallurgical engineering. Others were mining, petrochemical, petroleum, and public health engineering courses. Four environmental themes were completely absent in all of the programmes. Pollution was the prevalent environmental theme occurring 13 times in the document. The BMAS featured about $8 \%$ of the potential environmental content corresponding to $0.57 \%$ of the document (Table 3).

\section{Social content}

Figure 2 and Table 3 show the spread of the social concepts in the engineering programmes. Only four out of 12 social topics were mentioned in nine programmes with health \& safety being the most recurring theme. Eight social themes did not feature in any of the courses. Thus, just about $3 \%$ of the potential social content, which was equivalent to $0.45 \%$ of the BMAS document, featured in the engineering programmes.

\section{Crosscutting content}

The distribution of the cross-cutting themes within the BMAS involved seven engineering disciplines as shown in Figure 1. Only four of 10 cross-cutting topics were addressed. The themes of communication, reporting, ethics \& philosophy featured most frequently in the programmes. Six cross-cutting themes did not appear in any of the courses. Hence, $6 \%$ of the potential crosscutting content corresponding to $0.45 \%$ of the BMAS was covered in the document (Table 3 ).

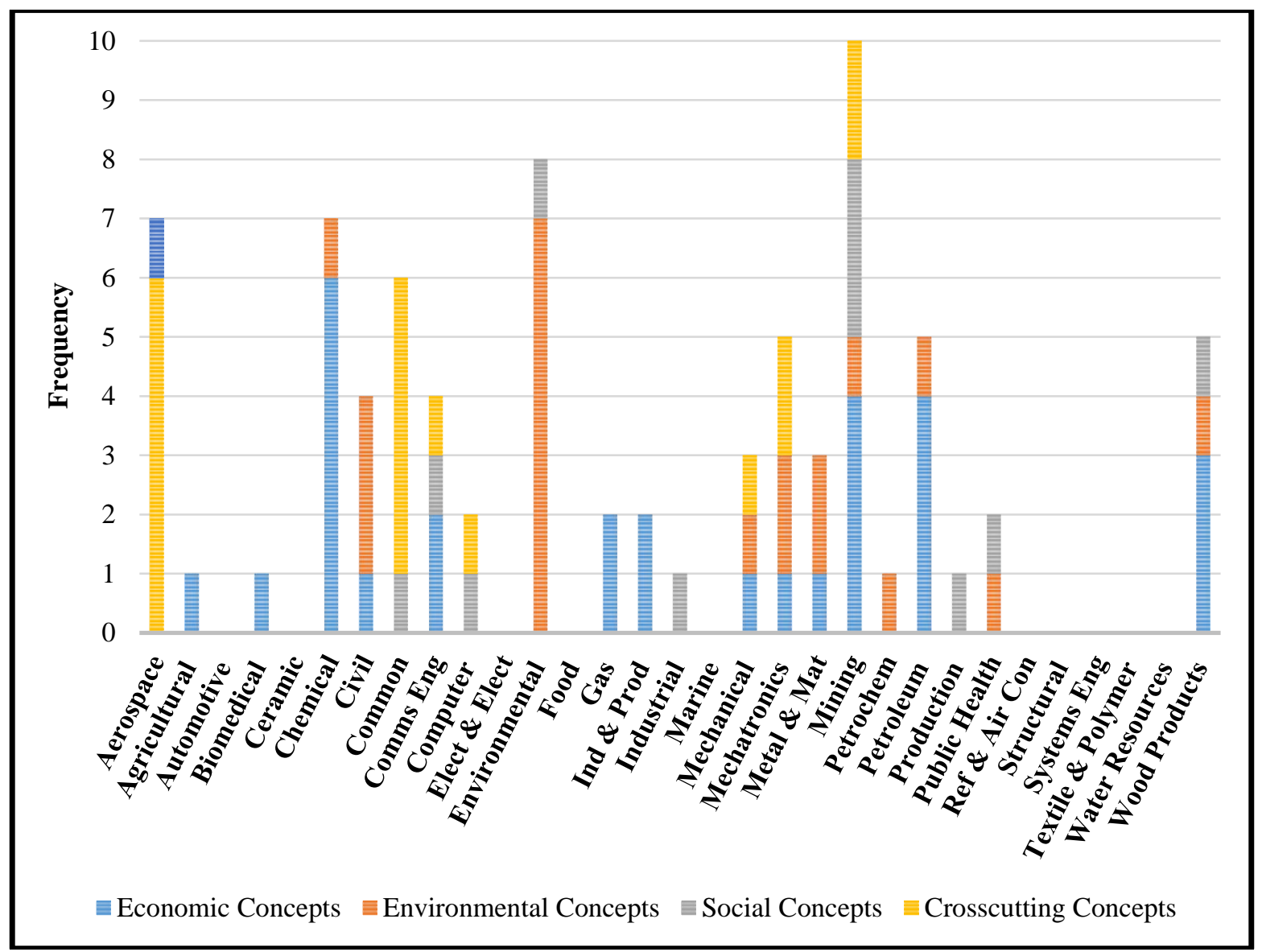

Figure 1. Distribution of sustainability topics in the BMAS document 
Table 3. Descriptive statistics of BMAS sustainability content

\begin{tabular}{|c|c|c|c|}
\hline Economic Concept & Frequency & $\begin{array}{l}\text { Expected } \\
\text { Occurrence }\end{array}$ & $\begin{array}{c}\% \text { within Potential } \\
\text { Content }\end{array}$ \\
\hline
\end{tabular}

\begin{tabular}{|c|c|c|c|c|}
\hline & & & & \\
\hline Accountability & 5 & 31 & 16.13 & 0.20 \\
\hline Dev economics & 3 & 31 & 9.67 & 0.14 \\
\hline Production patterns & 13 & 31 & 41.93 & 0.34 \\
\hline Finances & 4 & 31 & 12.90 & 0.11 \\
\hline Resource use & 4 & 31 & 12.90 & 0.10 \\
\hline GNP & 0 & 31 & 0.00 & 0.00 \\
\hline Economic content & 29 & 186 & 15.59 & 0.65 \\
\hline \multicolumn{5}{|l|}{ Environmental Concept } \\
\hline Alternative energy & 2 & 31 & 6.45 & 0.08 \\
\hline Biodiversity & 0 & 31 & 0.00 & 0.00 \\
\hline Climate change & 0 & 31 & 0.00 & 0.00 \\
\hline Land use & 0 & 31 & 0.00 & 0.00 \\
\hline Policy \& admin & 1 & 31 & 3.22 & 0.03 \\
\hline Pollution & 13 & 31 & 41.94 & 0.43 \\
\hline Products \& services & 3 & 31 & 9.68 & 0.08 \\
\hline Resource efficiency & 2 & 31 & 6.45 & 0.05 \\
\hline Resource depletion & 0 & 31 & 0.00 & 0.00 \\
\hline Environmental content & 21 & 279 & 7.53 & 0.57 \\
\hline \multicolumn{5}{|l|}{ Social Concept } \\
\hline Bribery \& corruption & 0 & 31 & 0.00 & 0.00 \\
\hline Culture \& religion & 0 & 31 & 0.00 & 0.00 \\
\hline Demography & 0 & 31 & 0.00 & 0.00 \\
\hline Diversity \& cohesion & 0 & 31 & 0.00 & 0.00 \\
\hline Education and training & 0 & 31 & 0.00 & 0.00 \\
\hline Employment & 1 & 31 & 3.22 & 0.06 \\
\hline Equity \& justice & 2 & 31 & 6.45 & 0.15 \\
\hline Health \& safety & 6 & 31 & 19.35 & 0.16 \\
\hline Labour \& human right & 2 & 31 & 6.45 & 0.14 \\
\hline Peace \& security & 0 & 31 & 0.00 & 0.05 \\
\hline Politics & 0 & 31 & 0.00 & 0.00 \\
\hline Poverty & 0 & 31 & 0.00 & 0.00 \\
\hline Social content & 11 & 372 & 2.96 & 0.45 \\
\hline \multicolumn{5}{|l|}{ Crosscutting Concept } \\
\hline Comm \& reporting & 7 & 31 & 22.58 & 0.05 \\
\hline Ethics \& philosophy & 7 & 31 & 22.58 & 0.25 \\
\hline Governance & 0 & 31 & 0.00 & 0.00 \\
\hline Holistic thinking & 0 & 31 & 0.00 & 0.00 \\
\hline Long-term thinking & 1 & 31 & 3.22 & 0.14 \\
\hline People: part of nature & 0 & 31 & 0.00 & 0.00 \\
\hline Responsibility & 4 & 31 & 12.90 & 0.21 \\
\hline Sustainability & 0 & 31 & 0.00 & 0.00 \\
\hline Systems thinking & 0 & 31 & 0.00 & 0.00 \\
\hline Transparency: design & 0 & 31 & 0.00 & 0.00 \\
\hline Cross-cutting content & 19 & 310 & 6.13 & 0.48 \\
\hline
\end{tabular}

* Obtained using the formula:

(Frequency/Expected Occurrence) X 100
** Obtained directly from NVivo calculations as average of characters and page area percentages 


\section{BMAS sustainability content}

The sustainability content of the BMAS can be determined by collating the results from the analysis of the sustainability themes. The results showed that the BMAS document had, on average, an extremely low sustainability content. Achieving only $8 \%$ of its potential coverage and contained in merely $2 \%$ of the entire document, sustainability theme did not receive much attention in the BMAS manual. However, economic topics were mentioned more than environmental, crosscutting and social themes respectively. Social issues were the least addressed themes in the BMAS document. Additionally, there was no engineering programme that featured all the subtopics of the sustainability themes.

\section{HEI-1 engineering handbook}

HEI-1 is a public university in Nigeria offering 10 engineering programmes domiciled in seven departments. The results of the sustainability content analysis of its engineering handbook are presented below.

\section{Economic content}

The economic content of the HEI-1 engineering handbook was spread across six engineering programmes as shown in Figure 2. The most frequently mentioned economic theme was production \& consumption patterns, which occurred five times within three disciplines: chemical, electrical/electronic and mechanical engineering. Two themes, namely GNP and resource use \& efficiency were not contained in any of the engineering programmes. None of the programmes featured more than two themes, although accountability and developmental economics were addressed in the common courses. Nonetheless, from Table 4, about $18 \%$ of the potential economic content was covered in the handbook, which corresponded to $1.60 \%$ of the entire engineering document. Thus, the HEI-1 engineering handbook had a somewhat fair economic content.

\section{Environmental content}

Spread of the environmental concepts in the HEI-1 engineering handbook occurred across seven engineering programmes as indicated in Figure 2. The themes of resource use, energy \& water and alternative energy were prevalent in the engineering manual. However, four of nine environmental themes did not appear in any of the programmes. The exclusions were climate change, resource ecoefficiency, biodiversity and products \& toxic wastes. Interestingly, environmental engineering, even though, covered all the five featured themes, also failed to include the three omissions. Overall, a significant part of the potential environmental content (31\%), equivalent to $4 \%$ of the engineering handbook, was attained in the document (Table 4).

\section{Social content}

The results of the social content of the HEI-1 engineering handbook are presented in Figure 2 and Table 4. With the exception of health \& safety and employment, no social topic was mentioned in the handbook. These two of 12 social themes were covered in six engineering programmes with only electrical and electronics engineering featuring employment issues. In general, the social content of the HEI-1 engineering handbook was quite low with merely $5 \%$ of its potential attained, which equated to about $1 \%$ of the whole engineering document.

\section{Crosscutting content}

Crosscutting concepts were spread across seven fields in the HEI-1 engineering handbook (Figure 2 and Table 4). However, only half of the themes were mentioned with communication \& reporting and ethics \& philosophy being prevalent. Three of the featured themes appeared in the common courses whilst 4 topics were contained in metallurgical engineering. Generally, the crosscutting theme had $15 \%$ of its potential content, corresponding to $0.85 \%$ of the entire engineering handbook, covered. 
HEI-1 engineering handbook sustainability content

Table 5 presents a summary of the sustainability content of HEI-1 engineering handbook. The results showed that the engineering handbook had a generally low sustainability content with just $17 \%$ potential attained, i.e., $7 \%$ of the HEI-1 engineering handbook. Nonetheless, environmental themes were the most frequently mentioned topics accounting for half of the document's sustainability coverage. In addition, the cross-cutting themes had the least coverage $(0.85 \%)$, but the social concepts were the least dispersed across the disciplines. Interestingly, metallurgical \& materials engineering featured at least one subtheme of all the sustainability themes.

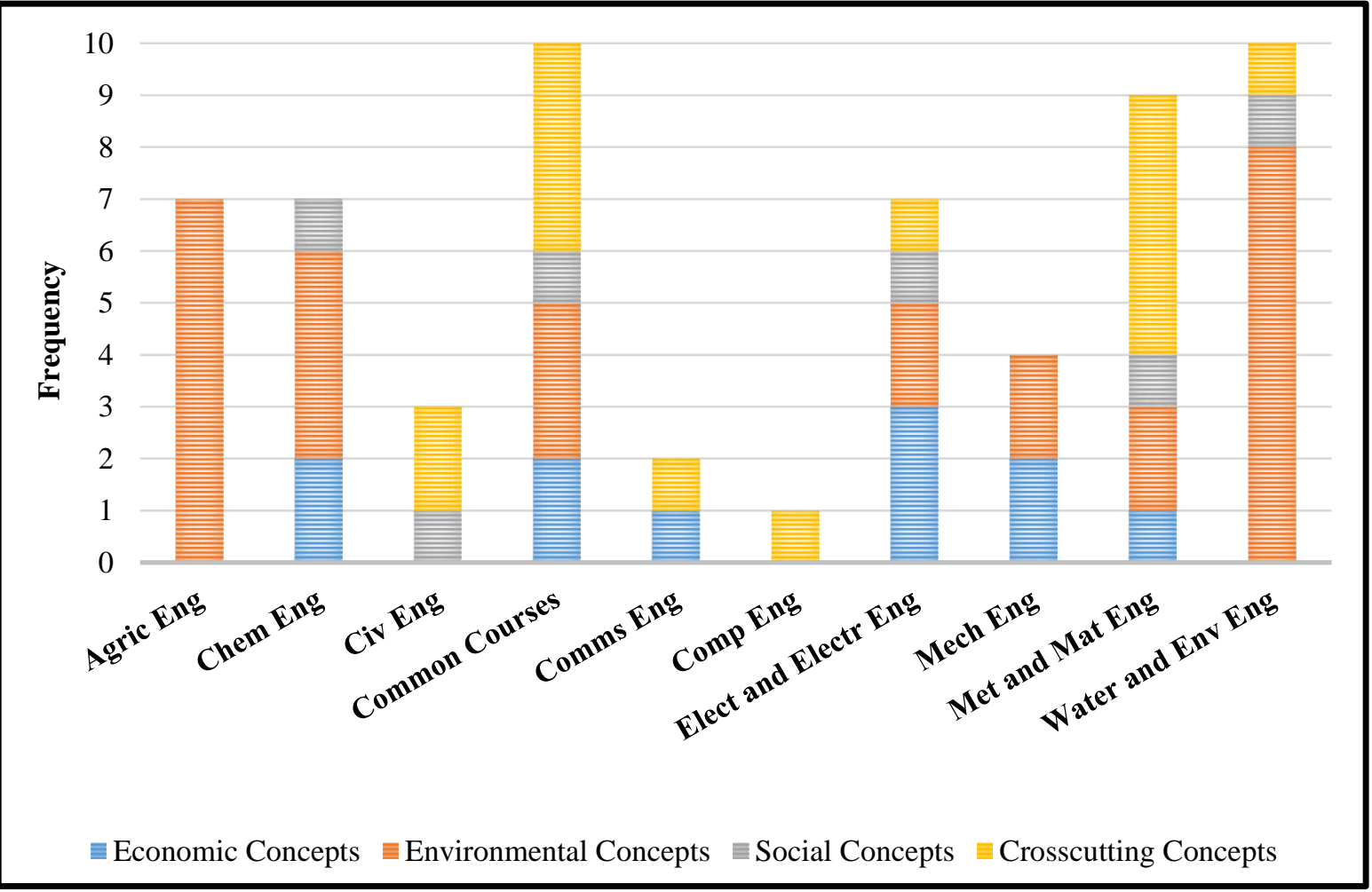

Figure 2. Distribution of sustainability topics in HEI-1 engineering handbook

Table 4. Descriptive statistics of HEI-1 sustainability content

\begin{tabular}{lcccc}
\hline Economic Concept & Frequency & $\begin{array}{c}\text { Expected } \\
\text { Occurrence }\end{array}$ & $\begin{array}{c}\text { \% within Potential } \\
\text { Content }\end{array}$ & $\begin{array}{c}\text { \% within } \\
\text { HEI-1 } \\
\text { Document** }\end{array}$ \\
\hline Accountability & 3 & 10 & 30.00 & 0.43 \\
\hline Dev economics & 2 & 10 & 20.00 & 0.04 \\
\hline Production patterns & 5 & 10 & 50.00 & 0.91 \\
\hline Finances & 1 & 10 & 10.00 & 0.21 \\
\hline Resource use & 0 & 10 & 0.00 & 0.00 \\
\hline GNP & 0 & 10 & 0.00 & 0.00 \\
\hline Economic content & 11 & 60 & 18.33 & 1.60 \\
\hline Environmental Concept & & & & 0.46 \\
\hline Alternative energy & 7 & 10 & 70.00 & 0.00 \\
\hline Biodiversity & 0 & 10 & 0.00 & 0.00 \\
\hline Climate change & 0 & 10 & 0.00 & 0.28 \\
\hline Land use & 2 & 10 & 20.00 & 1.31 \\
\hline Policy \& admin & 5 & 10 & 50.00 & 0.00 \\
\hline Pollution & 6 & 10 & 60.00 & 0.00 \\
\hline Products \& services & 0 & 10 & 0.00 & 1.13 \\
\hline Resource efficiency & 0 & 10 & 0.00 & \\
\hline Resource depletion & 8 & 10 & 80.00 & \\
\hline
\end{tabular}




\begin{tabular}{llccc}
\hline Environmental content & 28 & 90 & 31.11 & 3.55 \\
\hline Social Concept & & & & \\
\hline Bribery \& corruption & 0 & 10 & 0.00 & 0.00 \\
\hline Culture \& religion & 0 & 10 & 0.00 & 0.00 \\
\hline Demography & 0 & 10 & 0.00 & 0.00 \\
\hline Diversity \& cohesion & 0 & 10 & 0.00 & 0.00 \\
\hline Education and training & 0 & 10 & 10.00 & 0.16 \\
\hline Employment & 1 & 10 & 0.00 & 0.00 \\
\hline Equity \& justice & 0 & 10 & 50.00 & 0.98 \\
\hline Health \& safety & 5 & 10 & 0.00 & 0.00 \\
\hline Labour \& human right & 0 & 10 & 0.00 & 0.00 \\
\hline Peace \& security & 0 & 10 & 0.00 & 0.00 \\
\hline Politics & 0 & 10 & 0.00 & 0.00 \\
\hline Poverty & 0 & 10 & 5.00 & 0.13 \\
\hline Social content & 6 & 120 & 50.00 & 0.38 \\
\hline Crosscutting Concept & & & 40.00 & 0.00 \\
\hline Comm \& reporting & 5 & 10 & 0.00 & 0.00 \\
\hline Ethics \& philosophy & 4 & 10 & 0.00 & 0.00 \\
\hline Governance & 0 & 10 & 0.00 & 0.01 \\
\hline Holistic thinking & 0 & 10 & 20.00 & 0.27 \\
\hline Long-term thinking & 0 & 10 & 30.00 & 0.00 \\
\hline People: part of nature & 2 & 10 & 0.00 & 0.00 \\
\hline Responsibility & 3 & 10 & 0.00 & 0.15 \\
\hline Sustainability & 0 & 10 & 10.00 & \\
\hline Systems thinking & 0 & 10 & & \\
\hline Transparency: design & 1 & 10 & & \\
\hline Cross-cutting content & 15 & 100 & Obtained directly from NVivo calculations as average of \\
\hline * Obtained using the formula: & & & & \\
(Frequency/Expected Occurrence) & $X 100$ & characters and page area percentages & \\
\hline
\end{tabular}

\section{HEI-2 engineering handbook}

HEI-2 is an engineering institution in Nigeria which offers three engineering programmes. The succeeding paragraphs present the results of the sustainability content analysis of the engineering handbook of the institution.

Economic content

Economic concepts were poorly featured in HEI-2 engineering handbook as shown in Figure 3 and Table 5. Only the subtheme of accountability appeared in two disciplines contained in the document, namely civil and electrical/electronic engineering, and the common courses. Based on the potential economic content of the curriculum, only a fraction (12\%), corresponding to $0.60 \%$ of the document, was featured.

\section{Environmental content}

The distribution of environmental themes in the HEI-2 engineering handbook occurred across two disciplines as indicated in Figure 3. Four of 9 environmental themes featured chiefly in civil engineering courses with only resource use, energy \& water mentioned in electrical \& electronics engineering. Overall, the environmental coverage of the engineering handbook was low at $14 \%$ potential content and $1 \%$ of the document (Table 5).

\section{Social content}

The HEI-2 engineering handbook featured three of 12 social themes (Figure 3). Only civil engineering and common courses contained these topics. Thus, the social coverage of the 
engineering handbook was low as just $12 \%$ of its potential content (equivalent to $0.66 \%$ of the handbook) was attained (Table 5).

\section{Crosscutting Content}

Four cross-cutting themes spread across the four engineering programmes contained in HEI-2 engineering handbook as indicated in Figure 3. The subtheme of ethics \& philosophy recurred in all the programmes. In terms of potential content, the cross-cutting themes attained about one-fifth (20\%) coverage corresponding to $1.33 \%$ of the whole engineering handbook (Table 5).

\section{HEI-2 engineering handbook sustainability content}

Table 5 presents a summary of the sustainability content of HEI-2 engineering handbook. The results showed that the engineering handbook had a generally low sustainability content barely attaining $15 \%$ of its potential content, equivalent to $4 \%$ of the engineering document. However, cross-cutting themes were the most recurring topics with subthemes cited in all three engineering programmes including the common courses. The discipline of mechanical engineering featured only one subtheme of the cross-cutting concepts.

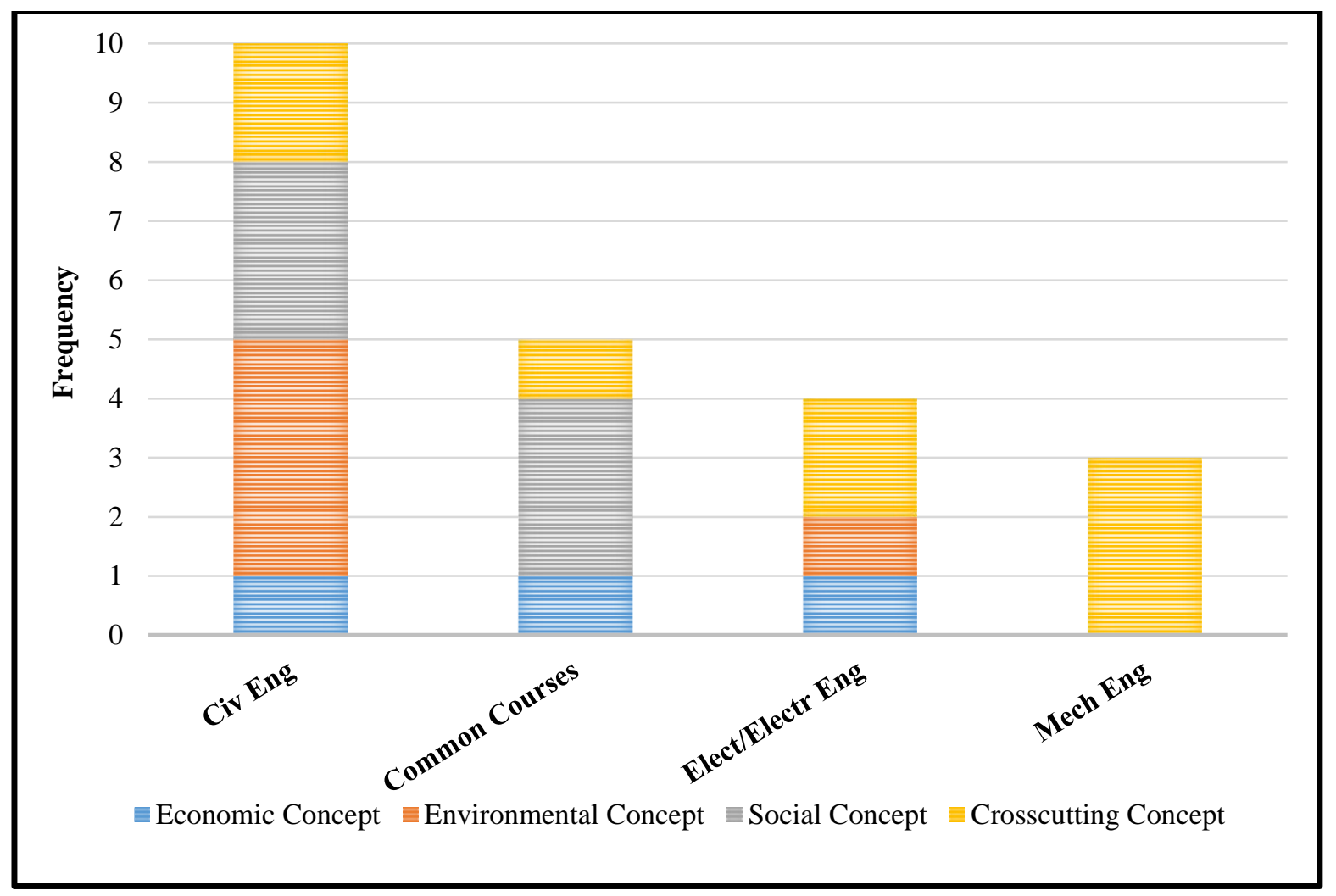

Figure 3. Distribution of sustainability topics in HEI-2 engineering handbooks

Table 5. Descriptive statistics of HEI-2 sustainability content

\begin{tabular}{lcccc}
\hline Economic Concept & Frequency & $\begin{array}{c}\text { Expected } \\
\text { Occurrence }\end{array}$ & $\begin{array}{c}\text { \% within Potential } \\
\text { Content }^{*}\end{array}$ & $\begin{array}{c}\text { \% within } \\
\text { HEI-2 } \\
\text { Document }^{* *}\end{array}$ \\
\hline Accountability & 3 & 4 & 75.00 & 0.60 \\
\hline Dev economics & 0 & 4 & 0.00 & 0.00 \\
\hline Production patterns & 0 & 4 & 0.00 & 0.00 \\
\hline Finances & 0 & 4 & 0.00 & 0.00 \\
\hline Resource use & 0 & 4 & 0.00 & 0.00 \\
\hline GNP & 0 & 4 & 0.00 & 0.00 \\
\hline Economic content & $\mathbf{3}$ & $\mathbf{2 4}$ & $\mathbf{1 2 . 5}$ & $\mathbf{0 . 6 0}$ \\
\hline Environmental Concept & & & & 0.00 \\
\hline Alternative energy & 0 & 4 & &
\end{tabular}




\begin{tabular}{|c|c|c|c|c|}
\hline Biodiversity & 0 & 4 & 0.00 & 0.00 \\
\hline Climate change & 0 & 4 & 0.00 & 0.00 \\
\hline Land use & 0 & 4 & 0.00 & 0.00 \\
\hline Policy \& admin & 1 & 4 & 25.00 & 0.17 \\
\hline Pollution & 1 & 4 & 25.00 & 0.14 \\
\hline Products \& services & 1 & 4 & 25.00 & 0.20 \\
\hline Resource efficiency & 0 & 4 & 0.00 & 0.00 \\
\hline Resource depletion & 2 & 4 & 50.00 & 0.76 \\
\hline Environmental content & 5 & 36 & 13.88 & 1.06 \\
\hline \multicolumn{5}{|l|}{ Social Concept } \\
\hline Bribery \& corruption & 0 & 4 & 0.00 & 0.00 \\
\hline Culture \& religion & 2 & 4 & 50.00 & 0.20 \\
\hline Demography & 0 & 4 & 0.00 & 0.00 \\
\hline Diversity \& cohesion & 0 & 4 & 0.00 & 0.00 \\
\hline Education and training & 2 & 4 & 50.00 & 0.15 \\
\hline Employment & 0 & 4 & 0.00 & 0.00 \\
\hline Equity \& justice & 0 & 4 & 0.00 & 0.00 \\
\hline Health \& safety & 0 & 4 & 0.00 & 0.00 \\
\hline Labour \& human right & 0 & 4 & 0.00 & 0.00 \\
\hline Peace \& security & 0 & 4 & 0.00 & 0.00 \\
\hline Politics & 2 & 4 & 50.00 & 0.30 \\
\hline Poverty & 0 & 4 & 0.00 & 0.00 \\
\hline Social content & 6 & 48 & 12.50 & 0.66 \\
\hline \multicolumn{5}{|l|}{ Crosscutting Concept } \\
\hline Comm \& reporting & 1 & 4 & 25.00 & 0.05 \\
\hline Ethics \& philosophy & 4 & 4 & 100.00 & 0.66 \\
\hline Governance & 0 & 4 & 0.00 & 0.00 \\
\hline Holistic thinking & 0 & 4 & 0.00 & 0.00 \\
\hline Long-term thinking & 2 & 4 & 50.00 & 0.19 \\
\hline People: part of nature & 0 & 4 & 0.00 & 0.00 \\
\hline Responsibility & 1 & 4 & 25.00 & 0.42 \\
\hline Sustainability & 0 & 4 & 0.00 & 0.00 \\
\hline Systems thinking & 0 & 4 & 0.00 & 0.00 \\
\hline Transparency: design & 0 & 4 & 0.00 & 0.00 \\
\hline Cross-cutting content & 8 & 40 & 20.00 & 1.33 \\
\hline
\end{tabular}

\section{Result synthesis}

Results of the documentary sustainability content analysis of the three engineering manuals are harmonised. The synthesis is aimed at approximating the sustainability content of the Nigerian engineering curriculum. Table 6 summarises the results of the sustainability content analyses. Mentions of sustainability themes differed in emphasis from one theme to another across the documents. In the BMAS document, for example, economic theme had the highest percentage coverage, which differed from HEI-1 and HEI-2 engineering handbooks that emphasised environmental and crosscutting topics respectively. Social theme received second lowest coverage in both HEI-1 and HEI-2 engineering handbooks, and worst coverage in the BMAS document. Crosscutting and economic themes were the worst covered sustainability topics in the HEI-1 and HEI-2 engineering handbooks respectively. Largely, sustainability themes were featured mainly in non-core courses such as engineering management. Only the BMAS document explicitly mentioned sustainability competence as a learning outcome for an engineering graduate. Overall, the sustainability content of the programmes based on the documentary analysis was low at a mean spread of $4.3 \%$ (13.37\% average potential content). 
Table 6. Summary of documentary sustainability content

\begin{tabular}{lccccc}
\hline Document & $\begin{array}{c}\text { Economic } \\
\% \text { coverage }\end{array}$ & $\begin{array}{c}\text { Environmental } \\
\% \text { coverage }\end{array}$ & $\begin{array}{c}\text { Social } \\
\text { \% coverage }\end{array}$ & $\begin{array}{c}\text { Crosscutting } \\
\% \text { coverage }\end{array}$ & $\begin{array}{c}\text { Sustainability } \\
\text { \% coverage }\end{array}$ \\
\hline BMAS & $0.65(15.59)^{*}$ & $0.57(7.53)^{*}$ & $0.45(2.96)^{*}$ & $0.48(6.13)^{*}$ & $2.15(8.05)^{*}$ \\
\hline $\begin{array}{l}\text { HEI-1 } \\
\text { EngHandbook }\end{array}$ & $1.60(18.33)^{*}$ & $3.55(31.11)^{*}$ & $1.13(5.00)^{*}$ & $0.85(15.00)^{*}$ & $7.13(17.36)^{*}$ \\
\hline $\begin{array}{l}\text { HEI-2 } \\
\text { EngHandbook }\end{array}$ & $0.60(12.50)^{*}$ & $1.06(13.88)^{*}$ & $0.66(12.50)^{*}$ & $1.33(20.00)^{*}$ & $3.65(14.72)^{*}$ \\
\hline \multicolumn{1}{c}{ Mean } & $\mathbf{1 . 0}(\mathbf{1 5 . 4 7})$ & $\mathbf{1 . 7}(\mathbf{1 7 . 4 8})$ & $\mathbf{0 . 7}(\mathbf{6 . 8 2})$ & $\mathbf{0 . 9}(\mathbf{1 3 . 7 1})$ & $\mathbf{4 . 3 ( 1 3 . 3 7 )}$ \\
\hline
\end{tabular}

Note: * figure in parenthesis represents percentage within theme's potential content or coverage

\section{Discussion}

\section{General discussion}

Being the official benchmark for engineering programmes in Nigeria, the BMAS document guides the development of engineering curriculum in the HEIs. Assessing the BMAS for sustainability content is, therefore, crucial to providing a baseline on the spread of sustainability in Nigerian engineering education. In this study, HEI-1 and HEI-2 engineering handbooks have been assessed for sustainability content alongside the BMAS document. Whilst the official BMAS contains 30 engineering programmes, HEI-1 and HEI-2 handbooks feature nine and three engineering courses respectively. Averagely, all three documents have shown low sustainability content based on the potential sustainability coverage of the documents and programmes. A noteworthy observation from the findings relates to the problem of overlapping topics in the engineering curriculum. The findings, for example, suggest the prevalence of such environmental topics as water efficiency and alternative energy, and the infrequence of climate change. Since those environmental topics cannot be addressed outside the context of climate change, it is apt to assume the presence of climate change in the curriculum, albeit inexplicit. Thus, the underlying challenge of climate change, even though may not be evidently stated in the engineering handbooks, is necessarily addressed during engineering lessons involving those environmental topics.

Studies on the sustainability content of engineering curricula in African higher education are scant as sustainability is an emerging interest on the continent (Buckler and Creech, 2014). However, inadequate sustainability coverage has been reported in some of the studies that have been undertaken. In a generic sustainability study of 69 African institutions barely a quarter of the surveyed HEIs (25\%) admitted to integrating sustainability in their various programmes (GUNi et al., 2011). The extent of sustainability incorporation in the programmes is not stated. These findings are consistent with the works of Manteaw (2012), UNESCO (2014), and Etse and Ingley (2016) who discovered low sustainability presence in a number of African HEIs. The findings of the present study show that the status of sustainability in Nigerian engineering education may not be different from the rest of Africa. Consequently, UNEP assertion that sustainability is marginally treated in a few disciplines in African HEIs seems plausible (UNEP-MESA, 2009).

Outside the African continent in regions with a more visible sustainability education, research has revealed considerable sustainability presence in engineering programmes, albeit with room for improvement (Lozano and Watson, 2013; Watson et al., 2013). Most of the HEIs in the member countries of the Organisation for Economic Cooperation and Development (OECD) have made remarkable efforts to embed sustainability in the engineering curriculum (Coral, 2009). A recurring challenge of these initiatives is the disproportionate distribution of the sustainability dimensions in the curriculum. For some reason, environmental sustainability seemed to have been treated more than the economic or social dimensions of sustainability in most of the curricula studied (Byrne et al., 2010; Segalas et al., 2010; Sinnott and Thomas, 2012; Watson, 2013; Shields et al., 2014; Sivapalan, 2015). In the present work, sustainability themes are not distributed equally in the engineering documents. The BMAS document contains more economic themes than it 
mentions environmental, crosscutting or social concepts. HEI-1 engineering handbook covers more environmental issues than economic, crosscutting and social themes, whilst HEI-2 engineering handbook features crosscutting themes more than environmental, social and economic concepts.

This finding does not only suggest a lack of one-to-one match between the BMAS document and the engineering handbooks, but also reveals a tendency of the Nigerian engineering curriculum to follow the pattern of sustainability distribution observed in the OECD countries. Congruent with some pre-intervention studies (Azapagic et al., 2005; EESD-Observatory, 2006), the synthesised result of the present research shows that the Nigerian engineering curriculum has an evidently low sustainability content with environmental and social concepts as the most and least cited themes respectively. If this trend continues on the current trajectory, the problem of an imbalanced sustainability content in the Nigerian engineering curriculum is highly likely, even at the post-intervention stage. Hence, the Nigerian engineering curriculum requires an education plan that emphasises the balance of the sustainability pillars, but also provides for robustness checks at every stage of the intervention.

The low sustainability content of the Nigerian engineering curriculum is not an unexpected outcome as no decisive steps have been taken in Nigeria to embed sustainability into engineering education. Indeed, the present research was driven by the realisation that Nigeria has no extant sustainability education model (Akeel et al., 2017). The sparse sustainability concepts found in the Nigerian engineering curriculum have come mainly from the management and ethics courses - conventional units in engineering programmes (Holm et al., 2014). These standard modules are not purpose-designed for sustainability and therefore lack the necessary sustainability finesse. However, since the courses already feature some sustainability themes, a sustainability course or programme could subsume them as part of an effective intervention for the Nigerian engineering curriculum. This would provide an opportunity for bridging the gap in the sustainability content of the curriculum.

Regarding the discrepancy between the BMAS document and the engineering handbooks, a possible explanation could be the lack of a focused sustainability education agenda in the BMAS document. There are no clear-cut incentives in the BMAS manual for the HEIs to include sustainability in their engineering documents. Excepting the nonspecific learning outcome that an engineering graduate must have the ability "to consider the environment and sustainability in finding solutions to problems" (BMAS, 2014, p.20), the benchmark document has no clear sustainability strategy. Such inexplicit expectation, which is missing in the HEIs' engineering handbooks, coupled with the failure of the manual to feature sustainability issues as programme requirements might have contributed to the mismatch between the BMAS document and the engineering handbooks.

Interestingly, the discrepancy between the official and the operational documents raises the question of how the private HEIs in Nigeria might compare with their public counterparts in terms of sustainability in engineering education. Given the scant literature on the subject and the fact that the two HEIs studied in the present research are public universities, such a comparison is currently unachievable. However, GUNi et al. (2011, p.59) suggest that profit-driven HEIs in Africa are likely to run programmes "without paying much attention to their contribution to sustainable development." Whether such is the case with the Nigerian HEIs is difficult to ascertain. In any event, the arbitrary coverage of sustainability themes in the Nigerian engineering curriculum could be prevented by devising a purposeful, contextual and integrative national sustainability education framework.

\section{Comparison of UCL and Nigerian engineering curricula sustainability contents}

University College London (UCL) implemented the Integrated Engineering Programme (IEP) as an innovative pedagogical framework that facilitates the delivery of specialist and interdisciplinary engineering education(UCL-IEP, 2018). Within the interdisciplinary pedagogy, core engineering 
disciplines are taught in combination with crosscutting subjects, such as design and professional skills, connected systems, environmental engineering, and finance and accounting amongst others. An objective of the UCL IEP is to produce engineers with a grounding in the fundamentals of their chosen disciplines, but also skilful in leadership, teamwork, and communication. The IEP model is designed such that students register for a core discipline but engage in interdisciplinary exercises alongside the core subjects. Students select a set of three IEP minors in the first year that will be taught across the second and third years. Given that the IEP model is considered world leading in engineering education (Graham, 2018), a comparison of its sustainability content with that of the Nigerian engineering curriculum seems appropriate.

Table 7. Comparison of UCL and Nigerian engineering curricula sustainability contents

\begin{tabular}{|c|c|c|c|c|c|}
\hline \multirow[t]{2}{*}{ Engineering Programme } & \multicolumn{4}{|c|}{ Frequencies } & \multirow{2}{*}{$\begin{array}{l}\text { Sustainability } \\
\sum \text { (frequencies) }\end{array}$} \\
\hline & Economic & Environmental & Social & Crosscutting & \\
\hline $\begin{array}{l}\text { UCL Engineering } \\
\text { Curriculum }\end{array}$ & 38 & 78 & 45 & 129 & 290 \\
\hline $\begin{array}{l}\text { Nigerian Engineering } \\
\text { Curriculum }\end{array}$ & 22 & 24 & 15 & 19 & 80 \\
\hline
\end{tabular}

An analysis of the UCL engineering curriculum using the methodology employed in the present research revealed a considerable sustainability presence in the engineering curriculum. Table 7 shows a comparison of the two engineering curricula. Sustainability concepts appeared 290 times in the UCL engineering curriculum, corresponding to a $42 \%$ of the engineering syllabuses. The bulk of the sustainability content, however, is traceable to the UCL IEP minors. Intrinsically, the core engineering disciplines are typified by low sustainability presence. Comparatively, the UCL engineering curriculum has almost twice as many mentions of economic concepts as the Nigerian engineering curriculum. The environmental mentions in the Nigerian engineering curriculum are one-third of the environmental concepts in the UCL engineering curriculum. In addition, the social themes of sustainability are mentioned in the UCL engineering curriculum three times more than they featured in the Nigerian engineering curriculum. The frequency of the crosscutting concepts in the UCL engineering curriculum is seven times higher than that of the Nigerian engineering curriculum. The analysis of the sustainability content of the UCL engineering curriculum reveals another path to sustainability in engineering education, namely the IEP framework. This way of sustainability integration supports the view that there is no single universally effective means of incorporating sustainability in engineering education (Jowitt, 2004; UNESCO, 2005; Manteaw, 2012).

The dissimilarities between the UCL and Nigerian engineering curricula raise some pertinent questions including whether the UCL engineering students, by virtue of the UCL IEP model, are more sustainability literate than their counterparts in Nigeria. There is no definitive answer to the question since the present study did not assess the sustainability literacy of the engineering students. However, given that the UCL engineering sustainability content is mainly in the elective IEP minors, the sustainability awareness of the two sets of students may not differ significantly. It is conceivable that the minors chosen by a UCL engineering student might cumulatively have low sustainability content. The poor presence of sustainability in the core disciplines of the UCL and the Nigerian engineering curricula underscores the difficulty of suffusing specialised fields with sustainability topics. This fact has been copiously reported in the literature which adduce the packed nature of the engineering curriculum as a contributing factor (Allenby, 2007; Sherren, 2007; Sivapalan, 2015).

Recognising such a difficulty, some researchers (Jowitt, 2004; Segalas et al., 2009; Hopkinson and James, 2010; Sheehan et al., 2012) have proposed various competency-driven frameworks. Jowitt (2004, p.86) maintains that rather than "shoving more material into an already overcrowded curriculum", a focus on the learning process and the systems perspective will be an effective 
strategy of sustainability inclusion in engineering education. The UCL IEP framework exemplifies such a recalibration of the engineering learning process that has yielded some sustainability content. However, since it is not mainly informed by an explicit sustainability worldview, it can only go so far as evidenced in the present study. The implication for the Nigerian engineering curriculum is the need to combine proportionately content and process to attain an optimum level of sustainability content that can guarantee sustainability literacy amongst Nigerian engineering graduates.

\section{Limitations}

The sustainability assessment approach adopted in the study is constrained by the problem of defining sustainability content - the question of what constitutes a sustainability syllabus or course. Consequently, how to measure the sustainability content of a pedagogical document is not unambiguous. Expert-derived sustainability themes as employed in this study are a useful means of gauging sustainability content. However, the resulting sustainability themes are ineluctably equivocal and the derived catalogue unavoidably incomplete. No expert listing of sustainability themes can be exhaustive enough to cover all aspects of sustainability, which is underlain by the fluidity of the sustainability concept. These inherent constraints may have limited the research's potential for a comprehensive appraisal of the sustainability content of the Nigerian engineering curriculum. Topics in the engineering documents that could qualify as sustainability content might have been overlooked for not fitting the $a$ priori codes derived from the sustainability themes.

Being derivatives of the well-established pillars of sustainability, the codes have been used effectively in similar studies around the world (Segalas et al., 2010; Lozano and Watson, 2013; Watson et al., 2013; de Pauw et al., 2014). These investigations are, nonetheless, in postintervention contexts in which oversight of a potentially qualified sustainability idea is more likely than in a pre-intervention context, such as the present study. The post-intervention context could contain certain sustainability ideas that may not necessarily align with the expert-derived themes, whereas the pre-intervention state may be completely bereft of sustainability themes. Therefore, any sustainability-related ideas or subjects in the pre-intervention contexts will be reasonably conspicuous. Consequently, the a priori codes were suitable for the baseline sustainability content assessment undertaken in the present study, and also appropriate for appraising a presustainability-intervention engineering curriculum.

\section{Conclusion}

Results of a sustainability content analysis of the Nigerian engineering curriculum were presented in the paper. The assessment involved the official BMAS document for accrediting engineering programmes and engineering curriculum documents from two Nigerian HEIs. These data were tested against 37 sustainability topics obtained from an expert-derived list of sustainability themes. An outcome of the study was that the sustainability content of the engineering programmes based on the documentary analysis was low at a mean spread of $4.3 \%(13.37 \%$ average potential content). Furthermore, environmental concepts were the most cited sustainability themes, whilst social topics were the least stated issues in the curriculum. Most of the featured sustainability topics appeared in the traditional engineering management courses. Only the BMAS document mentioned sustainability competence as an expected learning outcome for engineering graduates. A comparative look at the sustainability contents of the UCL and Nigerian engineering curricula revealed a similarity in the core disciplines, but with the UCL engineering curriculum through the IEP model containing more sustainability topics. Nonetheless, the efficacy of such content in terms of students' sustainability literacy cannot be guaranteed. Overall, the findings confirmed the need for a sustainability education intervention for the Nigerian engineering curriculum. 


\section{References}

AAU (2009) 'Abuja Declaration on Sustaianble Development in Africa: The Role of Higher Education', 12th General Conference of Association of African Universities. Abuja, Nigeria: African Union, p. 2. doi: 10.1089/SUS.2009.9822.

Akeel, U., Bell, S. and Mitchell, J. (2017) 'Engineering and sustainability education in Nigeria', in Quadrado, J., Bernardino, J., and Rocha, J. (eds) Proceedings of the 45th SEFI Annual Conference 2017 - Education Excellence for Sustainability, SEFI 2017. Azores - Portugal: ISEPSEFI.

Akeel, U. U. (2011) The Need to Establish Systems Engineering Department in Nigerian Air Force Institute of Technology. Kaduna.

Akinsanya, O. A. (2013) 'Falling Standard of Engineering Education in Nigeria- Causes and suggestions', International Journal of Advancements in Research \& technology, 2(10), pp. 93-96. Allenby, B. (2007) 'Sustainable Engineering Education: Translating Myth to Mechanism', Environmental Quality Management, 17(1), pp. 17-26. doi: 10.1002/tqem.20148.

Azapagic, A., Perdan, S. and Shallcross, D. (2005) 'How much do engineering students know about sustainable development? The findings of an international survey and possible implications for the engineering curriculum', European Journal of Engineering Education, 30(1), pp. 1-19. doi: 10.1080/03043790512331313804.

Beringer, A., Wright, T. and Malone, L. (2008) 'Sustainability in higher education in Atlantic Canada', International Journal of Sustainability in Higher Education, 9(1), pp. 48-67.

BMAS (2014) 'Benchmark minimum academic standards and accreditation scoring criteria for undergraduate engineering programmes in Nigerian universities'. Abuja, Nigeria: Council for the Regulation of Engineering in Nigeria, p. 376.

Buckler, C. and Creech, H. (2014) Shaping the Future We Want. Paris: UNESCO. doi: 10.5363/tits.11.4_46.

Byrne, E. et al. (2010) 'Engineering education for sustainable development: A review of international progress', in 3rd International Symposium for Engineering Education. Cork, p. 42. Caeiro, S. et al. (2013) Sustainability assessment tools in higher education institutions: Mapping trends and good practices around the world. Switzerland: Springer International Publishing. doi: 10.1007/978-3-319-02375-5.

Carteron, J.-C. and Decamps, A. (2017) Mapping awareness of the global goals. New York.

Coral, J. S. (2009) Engineering Education for a Sustainable Future. Technical University of Catalonia.

Desha, C. et al. (2007) 'The Importance of Sustainability in Engineering Education: A Toolkit of Information and Teaching Material', Engineering Training \& Learning Conference, (June), pp. 1-14. Available at: http://www.naturaledgeproject.net/Documents/ICDPaper-Final.pdf.

EESD-Observatory (2006) The Observatory: Status of Engineering Education for Sustainable Development in European Higher Education, Education. Spain.

EESD (2004) EESD Barcelona Declaration| Engineering Education for Sustainable Development. Available at: http://eesd15.engineering.ubc.ca/declaration-of-barcelona/ (Accessed: 5 September 2016).

Engineering Council (2013) 'Guidance on sustainability for the engineering profession'. London: Engineering Council, pp. 1-7.

Etse, D. and Ingley, C. (2016) 'Higher education curriculum for sustainability: course contents analyses of purchasing and management programme of polytechnics in Ghana', International 
Journal of Sustainability in Higher Education, 17(2), pp. 269-280. doi: 10.1108/14676371311312905.

Fenner, R. A. et al. (2005) 'Embedding sustainable development at Cambridge University Engineering Department', International Journal of Sustainability in Higher Education, 6(3), pp. $229-241$.

FME (2016) 'Federal Ministry of Education Integrated Charter'. Abuja: Federal Ministry of Education - Nigeria, p. 34.

Graham, R. (2018) The global state of the art in engineering education. Massachusetts: Massachusetts Institute of Technology. Available at: https://jwel.mit.edu/assets/document/globalstate-art-engineering-education.

GUNi, IAU and AAU (2011) The promotion of sustainable development by higher education institutions in sub-Saharan Africa. Barcelona.

Holm, T., Vuorisalo, T. and Sammalisto, K. (2014) 'Integrated management systems for enhancing education for sustainable development in universities: a memetic approach', Journal of Cleaner Production, 106, p. 1-9Holm, T., Vuorisalo, T., Sammalisto, K. (2014. doi: 10.1016/j.jclepro.2014.03.048.

Hopkinson, P. and James, P. (2010) 'Practical pedagogy for embedding ESD in science, technology, engineering and mathematics curricula', International Journal of Sustainability in Higher Education, 11(4), pp. 365-379. doi: 10.1108/14676371011077586.

Idris, A. and Rajuddin, M. (2012) 'The Trend of Engineering Education in Nigerian Tertiary Institutions of Learning towards Achieving Technological Development', Procedia -Social and Behavioral Sciences, 56(Ictlhe), pp. 730-736. doi: 10.1016/j.sbspro.2012.09.710.

JAMB (2017) 'Guidelines for admissions into tertiary programmes in higer education institutions in Nigeria'. Abuja: Joint Admissions and Matriculation Board, p. 1032.

Jowitt, P. W. (2004) 'Systems and sustainability: sustainable development, civil engineering and the formation of the civil engineer', Engineering Sustainability, 157(ES2), pp. 79-88.

Kamp, L. (2006) 'Engineering education in sustainable development at Delft University of Technology', Journal of Cleaner Production, 14(9-11), pp. 928-931. doi: 10.1016/j.jclepro.2005.11.036.

Kotecki, C. N. (2002) 'the Curriculum', Nurse Educator, 27(1), pp. 13-15. doi: 10.1021/ed2006289.(3).

Lozano, F. J. and Lozano, R. (2014) 'Developing the curriculum for a new Bachelor's degree in Engineering for Sustainable Development', Journal of Cleaner Production. Elsevier Ltd, 64, pp. 136-146. doi: 10.1016/j.jclepro.2013.08.022.

Lozano, R. (2006) 'A tool for a Graphical Assessment of Sustainability in Universities (GASU)', Journal of Cleaner Production, 14(9-11), pp. 963-972. doi: 10.1016/j.jclepro.2005.11.041.

Lozano, R. and Watson, M. K. (2013) 'Chemistry Education for Sustainability: Assessing the chemistry curricula at Cardiff University’, Educacion Quimica. Elsevier, 24(2), pp. 184-192. doi: 10.1016/S0187-893X(13)72461-3.

Manteaw, O. O. (2012) 'Education for sustainable development in Africa: The search for pedagogical logic', International Journal of Educational Development, 32(3), pp. 376-383. doi: 10.1016/j.ijedudev.2011.08.005.

NUC (2018) National Universities Commission. Available at: http://nuc.edu.ng/nigerianuniverisities/federal-univeristies/ (Accessed: 15 June 2018).

de Pauw, I. C., Kandachar, P. and Karana, E. (2014) 'Assessing sustainability in nature-inspired 
design', International Journal of Sustainable Engineering, 7038(January 2015), pp. 1-9. doi: 10.1080/19397038.2014.977373.

Segalas, J. et al. (2009) 'What has to be learnt for sustainability? A comparison of bachelor engineering education competences at three European universities', Sustainability Science, 4(1), pp. 17-27. doi: 10.1007/s11625-009-0068-2.

Segalas, J., Ferrer-Balas, D. and Mulder, K. F. (2010) 'What do engineering students learn in sustainability courses? The effect of the pedagogical approach', Journal of Cleaner Production, 18(3), pp. 275-284. doi: 10.1016/j.jclepro.2009.09.012.

Sheehan, M., Schneider, P. and Desha, C. (2012) 'Implementing a systematic process for rapidly embedding sustainability within chemical engineering education : a case study of James Cook University, Australia', Chemical Education Research and Practice, 13(2), pp. 112-119. doi: $10.1039 / \mathrm{c} 1 \mathrm{rp} 90068 \mathrm{~d}$.

Sherren, K. (2007) 'Is there a sustainability canon? An exploration and aggregation of expert opinions', Environmentalist, 27(3), pp. 341-347. doi: 10.1007/s10669-007-9046-3.

Shields, D., Verga, F. and Blengini, G. A. (2014) 'Incorporating sustainability in engineering education: Adapting current practices to mining and petroleum engineering education', International Journal of Sustainability in Higher Education, 15(4), pp. 390-403.

Shriberg, M. (2002) 'Institutional assessment tools for sustainability in higher education', International Journal of Sustainability in Higher Education, 3(3), pp. 254-270. doi: 10.1108/14676371211211809.

Sinnott, D. and Thomas, K. (2012) 'Integrating Sustainability into Civil Engineering Education : Curriculum Development \& Implementation', (July). doi: 10.13140/RG.2.1.2064.6243.

Sivapalan, S. (2015) Engineering education for sustainable development for undergraduate engineering programmes in Malaysia: a stakeholder defined framework. The University of Nottingham.

Togo, M. (2009) A Systems Approach To Mainstreaming Environment and Sustainability in Universities: the Case of Rhodes University, South Africa. Rhodes University.

UCL-IEP (2018) UCL Integrated Engineering Programme: Structure Overview. Available at: http://www.engineering.ucl.ac.uk/integrated-engineering/programme-structure/ (Accessed: 13 August 2018).

UNEP-MESA (2009) 'Supporting Universities to Respond to Environment, Sustainable Development and Climate Change Challenges'. Nairobi: Publishing Services Section UNON Nairobi, p. 74.

UNESCO (2005) 'United Nations Decade of Education for Sustainable Development (2005-2014) International Implementation Scheme', Sustainable Development, (October 2005), p. 32. doi: 10.1007/s13398-014-0173-7.2.

Watson, M. K. et al. (2013) 'Assessing curricula contribution to sustainability more holistically: Experiences from the integration of curricula assessment and students' perceptions at the Georgia Institute of Technology', Journal of Cleaner Production, 61, pp. 106-116.

Watson, M. K. (2013) Assessment and improvement of sustainability education in civil and environmental engineering. Georgia Institute of Technology. PhD Thesis.

Watson, M. K., Noyes, C. and Rodgers, M. O. (2013) 'Student perceptions of sustainability education in civil and environmental engineering at the Georgia Institute of Technology', Journal of Professional Issues in Engineering Education and Practice, 139(3), pp. 235-243. doi: 10.1061/(ASCE)EI.1943-5541. 


\section{About the authors}

Usman Akeel holds a PhD in Engineering Sustainability from University College London in the United Kingdom. His research interests focus on sustainability in engineering education as well as engineering philosophy. He is currently a research engineer in the Civil and Environmental Engineering Department at the Air Force Institute of Technology, Kaduna, Nigeria.

Sarah Bell is Professor of Environmental Engineering in the Institute for Environmental Design and Engineering, and Director of the Engineering Exchange at UCL. She is a Chartered Engineer and Fellow of the Institution of Civil Engineers and Chartered Institution of Water and Environmental Managers. She is an EPSRC Living With Environmental Change Research Fellow, researching community engagement with infrastructure.

John E. Mitchell is Professor of Communications Systems Engineering in the UCL Department of Electronic and Electrical Engineering, Vice-Dean Education in the UCL Faculty of Engineering Sciences and Co-director of the UCL Centre for Engineering Education. Between 2012 and 2016 he was on secondment to the UCL Engineering Sciences Faculty office, where he led the introduction of the Integrated Engineering Programme. The team that led this major revision of the curriculum across the engineering faculty has recently been awarded the HEA Collaborative Award for Teaching Excellence (CATE). In 2009, he was awarded the UCL Provost's award for teaching and has published on curriculum development with engineering education. Professor Mitchell is a Chartered Engineer, Fellow of the Institution of Engineering and Technology (IET) a Senior Member of the Institute of Electrical and Electronics Engineers (IEEE), Member of the Board of Directors of the European Society for Engineering Education and Fellow of the Higher Education Academy. He is currently Editor-in-Chief of the IEEE Transactions on Education. 